Published in final edited form as:

Cell Dev Biol. 2012 ; 1(2): . doi:10.4172/2168-9296.

\title{
DNA Repair Defects and DNA-PK in Neurodegeneration
}

\author{
Jyotshna Kanungo* \\ Division of Neurotoxicology, National Center for Toxicological Research, US Food and Drug \\ Administration, Jefferson, AR 72079, USA
}

\section{Keywords}

Ku; DNA-PK; Alzheimer's disease; p53; DNA repair

\begin{abstract}
Mammalian brain consists of two major types of cells, the neurons and glia. Mature neurons are essentially post-mitotic and do not proliferate whereas some glial cells can undergo replication especially as a response to stress or damage [1,2]. Nervous system is one of the earliest systems to develop and differentiate in almost all the species. Therefore, literally, neurons in the brain are one of the oldest cell populations in the organism. Neurons are also one of the most metabolically active cells and gene expression is two- to threefold higher in neurons than in any other cell [3]. These non-dividing, metabolically hyperactive cells are, therefore, vulnerable to risks that involve DNA damage.
\end{abstract}

DNA repair pathways in brain have been studied extensively over the last two decades (reviews [4,5]). In mammals, DNA double-strand break (DSB) repair uses two mechanisms, homologous recombination (HR) and non-homologous DNA end joining (NHEJ). NHEJ is the predominant double-stranded DNA repair pathway in mammalian cells [6]. NHEJ is among the most recently defined repair pathways with substantial importance in cancer, aging and immune system development. Compared to the HR, NHEJ is considered errorprone and imprecise since it acts at the DNA break sites to restore the chromosomal structural integrity which could come at the expense of one or few nucleotides. Over time, as in aging, these small errors can accumulate resulting in genome instability leading to cellular dysfunction or death. Interestingly, it has been reported that $10 \%$ of p53 mutations in human cancers could be attributed to deletions arising from NHEJ sites [7].

NHEJ is also the predominant form of double-stranded DNA repair pathway in post-mitotic neurons [8]. DNA-dependent protein kinase, a complex of the DNA-dependent protein kinase catalytic subunit (DNA-PK $\mathrm{cs}_{\text {) }}$ and a heterodimer of $\mathrm{Ku} 70$ and $\mathrm{Ku} 80$, plays a principal role in NHEJ [9]. NHEJ is critical in the nervous system development since mice deficient in DNA Ligase IV, XRCC4, Ku70 and Ku 80 that are participants in the NHEJ event, show massive apoptosis in post-mitotic neurons $[4,10]$. When a DSB occurs, the Ku heterodimer

This is an open-access article distributed under the terms of the Creative Commons Attribution License, which permits unrestricted use, distribution, and reproduction in any medium, provided the original author and source are credited.

"Corresponding author: Jyotshna Kanungo, PhD, Division of Neurotoxicology, National Center for Toxicological Research, U.S Food and Drug Administration, 3900 NCTR Road, Jefferson, AR 72079, USA, Tel: 870-543-7591; Fax: 870-543-7143; jyotshnabala.kanungo@fda.hhs.gov. 
$(\mathrm{Ku} 80 / \mathrm{Ku} 70)$ binds to the broken ends first using Ku80 and then recruits the DNA-PK $\mathrm{cs}$ which is activated upon binding to Artemis nuclease and the repair process is completed by XRCC4-DNA ligase IV [11,12].

Loss of NHEJ activity in the developing brain can be prenatally lethal and in adults, can lead to neurodegenerative diseases $[4,13,14]$. The type of DNA damage most likely occurring in neurons is oxidative damage. High metabolic rate of neurons can generate excessive oxygen radicals and neurodegenerative diseases like Alzheimer's disease (AD) have been linked to oxidative stress (reviews $[4,15]$ ). The other aspect contributing to neuronal DNA damage is linked to neurons re-entering cell cycle $[16,17]$. When post-mitotic neurons try to re-enter the cell cycle, the very attempt to transcribe a subset of cell cycle-related genes that have not been transcribed for years in a mature neuron's lifetime may accumulate damaged DNA that could trigger neuronal apoptosis [18]. In neurodegenerative diseases like AD, the types of DNA damages are likely induced by reactive oxygen species (ROS) [19]. With aging, NHEJ activity gradually decreases as the neurons become terminally differentiated. However, in mature rats, the NHEJ activity in the brain is comparable to the level observed in the testes [20]. When a declining activity in the nervous system matches with the normal activity in another tissue (testis), it is conceivable that NHEJ activity during nervous system development could, in fact, be robust.

Once the neuron stops dividing, the need for DNA repair may be reduced and the necessity to maintain active NHEJ machinery may, as well, become obsolete. However, under oxidative stress or other endogenous or exogenous insults, when the neuronal DNA is damaged, due to a pre-existing reduced NHEJ activity, the neurons may undergo apoptosis or should they re-enter cell cycle, the damaged DNA could replicate thus compounding genomic aberration. Thus, in aging, the brain could harbor post-mitotic neurons with reduced NHEJ potential, but if not challenged with an insult, the neuron could die a normal death; whereas in neurodegenerative diseases like AD, factors, such as ROS, could trigger DNA damage and lacking its repair, neurons could degenerate prematurely. Because of a fine line between neurons in a normal aging brain and neurons in distress because of disposition to the neurodegenerative diseases, the proteins and enzymes involved in the NHEJ are worthy candidates for investigation.

DNA-PK plays a role in detecting DNA damage and triggering signaling pathways including programmed cell death [21]. $\mathrm{Ku} 80^{-/-}$mice are defective in the NHEJ and telomere maintenance and show premature aging, but surprisingly no human disorder caused by Ku80 deficiency or mutation has been reported [22,23]. Interestingly, Ku80 and DNA-PK cs $_{\text {p }}$ protein levels as well as Ku80's DNA-binding ability are reduced following severe ischemic injury that causes extensive neuronal death in rabbit [24]. Furthermore, although not significantly different from the age-matched controls, Ku-DNA binding is reduced in extracts of postmortem AD mid-frontal cortex, which could be attributed to reduced levels of Ku subunits and DNA-PK $\mathrm{cs}_{\mathrm{cs}}$ [25]. However, another report from the same laboratory demonstrated that NHEJ is reduced in cortical extracts from brains of AD versus normal subjects and DNA$\mathrm{PK}_{\mathrm{cs}}$ level was significantly lower in the AD brain extracts [24]. 
In order to make sense of the complexity of $\mathrm{AD}$, a 'two-hit hypothesis' for $\mathrm{AD}$ development has been reported, which states that the first hit makes neurons vulnerable and the second hit triggers the neurodegenerative process [26]. The first hit may constitute abnormalities when neurons try to re-enter cell cycle or oxidative stress, which, if persistent, can create a prooxidant environment as encountered in pre-AD and $\mathrm{AD}$ cases. In this environment, proteins highly sensitive to redox modulation, including p53, can be compromised [27]. A number of postmortem studies suggest an involvement of p53 in AD and high levels of p53 in certain neurons in postmortem samples from AD patients have been reported (review [28]). DNAPK activates p53 by phosphorylating the amino-terminal site [29] and p53 can induce Bax, a pro-apoptotic protein that translocates to the mitochondria and initiates the intrinsic death pathway [30]. Regulation of Bax-mediated neuronal death also reportedly involves Ku70 phosphorylation by DNA-PK [31]. In this regard, reduction in DNA-PK $\mathrm{Cs}_{\mathrm{cs}}$ levels in AD brains does not seem to fit in to the concept of it being the trigger for $\mathrm{p} 53$-mediated neurodegeneration.

Considered indispensable for $\mathrm{V}$ (D) $\mathrm{J}$ recombination in immune response cells utilizing NHEJ, DNA-PK is believed to have little or no effect in p53-dependent cell cycle arrest. In contrast, there are reports linking p53 phosphorylation by DNA-PK to cellular death machinery (review [32]). DNA-PK is also involved in regulating the activities of RNA Polymerase I and II via phosphorylation (review [32]). Given these important substrates of DNA-PK that are critical players in cell death and gene transcription, it is difficult to pinpoint the exact role(s) of DNA-PK $\mathrm{cs}_{\mathrm{s}}$ and its cofactor (Ku80/Ku70) in AD. Likewise, it would be simplistic to directly link reduced levels of DNA-PK subunits and consequently less proficient NHEJ in AD brains to neurodegeneration. On the other hand, it is attractive to speculate that DNA damage (e.g., induced by ROS downstream of A $\beta$ ) in neurons with reduced NHEJ activity, triggering them to re-enter cell cycle unsuccessfully, could lead to the accumulation of excessive genomic damage eventually causing neuron death. In either pathway, NHEJ being the process involved, the importance of DNA-PK $\mathrm{cs} / \mathrm{Kv}$ complex in the development of neurodegenerative pathology may be considerable. The reduced levels of DNA-PK $\mathrm{cs}_{\mathrm{cs}}$ and $\mathrm{Ku} 80 / \mathrm{Ku} 70$ subunits in postmortem AD brains may be perceived as upstream events of neuron loss in $\mathrm{AD}$, although further studies are warranted to differentiate between cause and consequence.

\section{References}

1. Lieber MR, Ma Y, Pannicke U, Schwarz K. Mechanism and regulation of human non-homologous DNA end-joining. Nat Rev Mol Cell Biol. 2003; 4:712-720. [PubMed: 14506474]

2. Korr H. Proliferation of different cell types in the brain. Adv Anat Embryol Cell Biol. 1980; 61:172. [PubMed: 7415890]

3. Ridet JL, Malhotra SK, Privat A, Gage FH. Reactive astrocytes: cellular and molecular cues to biological function. Trends Neurosci. 1997; 20:570-577. [PubMed: 9416670]

4. Tobin JR, Martin LD, Breslow MJ, Traystman RJ. Selective anesthetic inhibition of brain nitric oxide synthase. Anesthesiology. 1994; 81:1264-1269. [PubMed: 7526751]

5. Brooks PJ. DNA repair in neural cells: basic science and clinical implications. Mutat Res. 2002; 509:93-108. [PubMed: 12427533]

6. Rao KS. DNA repair in aging rat neurons. Neuroscience. 2007; 145:1330-1340. [PubMed: 17156934] 
7. Greenblatt MS, Grollman AP, Harris CC. Deletions and insertions in the p53 tumor suppressor gene in human cancers: confirmation of the DNA polymerase slippage/misalignment model. Cancer Res. 1996; 56:2130-2136. [PubMed: 8616861]

8. Rass U, Ahel I, West SC. Defective DNA repair and neurodegenerative disease. Cell. 2007; 130:991-1004. [PubMed: 17889645]

9. Lees-Miller SP, Meek K. Repair of DNA double strand breaks by non-homologous end joining. Biochimie. 2003; 85:1161-1173. [PubMed: 14726021]

10. Sekiguchi JM, Gao Y, Gu Y, Frank K, Sun Y, et al. Nonhomologous end-joining proteins are required for V(D)J recombination, normal growth, and neurogenesis. Cold Spring Harb Symp Quant Biol. 1999; 64:169-181. [PubMed: 11232282]

11. DeFazio LG, Stansel RM, Griffith JD, Chu G. Synapsis of DNA ends by DNA-dependent protein kinase. EMBO J. 2002; 21:3192-3200. [PubMed: 12065431]

12. Ma Y, Pannicke U, Schwarz K, Lieber MR. Hairpin opening and overhang processing by an Artemis/DNA-dependent protein kinase complex in nonhomologous end joining and V(D)J recombination. Cell. 2002; 108:781-794. [PubMed: 11955432]

13. McKinnon PJ, Caldecott KW. DNA strand break repair and human genetic disease. Annu Rev Genomics Hum Genet. 2007; 8:37-55. [PubMed: 17887919]

14. Yang Y, Herrup K. Loss of neuronal cell cycle control in ataxia-telangiectasia: a unified disease mechanism. J Neurosci. 2005; 25:2522-2529. [PubMed: 15758161]

15. Markesbery W. Oxidative stress hypothesis in Alzheimer's disease. Free Radic Biol Med. 1997; 23:134-147. [PubMed: 9165306]

16. Kruman II, Wersto RP, Cardozo-Pelaez F, Smilenov L, Chan SL, et al. Cell cycle activation linked to neuronal cell death initiated by DNA damage. Neuron. 2004; 41:549-561. [PubMed: 14980204]

17. McMurray CT. To die or not to die: DNA repair in neurons. Mutat Res. 2005; 577:260-274. [PubMed: 15921706]

18. Nouspikel T, Hanawalt PC. When parsimony backfires: neglecting DNA repair may doom neurons in Alzheimer's disease. Bioessays. 2003; 25:168-173. [PubMed: 12539243]

19. Poli M, Gatta LB, Archetti S, Padovani A, Albertini A, et al. Association analysis between anterior-pharynx defective-1 genes polymorphisms and Alzheimer's disease. Neurosci Lett. 2003; 350:77-80. [PubMed: 12972157]

20. Ren K, Pena de Ortiz S. Non-homologous DNA end joining in the mature rat brain. J Neurochem. 2002; 80:949-959. [PubMed: 11953445]

21. Smith GC, Jackson SP. The DNA-dependent protein kinase. Genes Dev. 1999; 13:916-934. [PubMed: 10215620]

22. Pandita TK. The role of ATM in telomere structure and function. Radiat Res. 2001; 156:642-647. [PubMed: 11604086]

23. Vogel H, Lim DS, Karsenty G, Finegold M, Hasty P. Deletion of Ku86 causes early onset of senescence in mice. Proc Natl Acad Sci U S A. 1999; 96:10770-10775. [PubMed: 10485901]

24. Shackelford DA. DNA end joining activity is reduced in Alzheimer's disease. Neurobiol Aging. 2006; 27:596-605. [PubMed: 15908050]

25. Davydov V, Hansen LA, Shackelford DA. Is DNA repair compromised in Alzheimer's disease? Neurobiol Aging. 2003; 24:953-968. [PubMed: 12928056]

26. Zhu X, Lee HG, Perry G, Smith MA. Alzheimer's disease: the two-hit hypothesis. Lancet Neurol. 2004; 3:219-226. [PubMed: 15039034]

27. Liu DG. Review of neuropathology in the past 10 years in China. Zhonghua Bing Li Xue Za Zhi. 2005; 34:550-552. [PubMed: 16468302]

28. Lanni C, Racchi M, Memo M, Govoni S, Uberti D. p53 at the crossroads between cancer and neurodegeneration. Free Radic Biol Med. 2012; 52:1727-1733. [PubMed: 22387179]

29. Soubeyrand S, Schild-Poulter C, Haché RJ. Structured DNA promotes phosphorylation of p53 by DNA-dependent protein kinase at serine 9 and threonine 18. Eur J Biochem. 2004; 271:37763784. [PubMed: 15355354]

30. Yee KS, Vousden KH. Complicating the complexity of p53. Carcinogenesis. 2005; 26:1317-1322. [PubMed: 15888490] 
31. Liu J, Naegele JR, Lin SL. The DNA-PK catalytic subunit regulates Bax-mediated excitotoxic cell death by Ku70 phosphorylation. Brain Res. 2009; 1296:164-175. [PubMed: 19664609]

32. Hill R, Lee PW. The DNA-dependent protein kinase (DNA-PK): More than just a case of making ends meet? Cell Cycle. 2010; 9:3460-3469. [PubMed: 20855954] 